\title{
Avaliação da adesão e aceitabilidade dos cardápios do Programa de Alimentação Escolar em escolas municipais de Itapetinga - BA: indicadores de desperdício de alimentos
}

\author{
Accession assessment and acceptability of the School Feeding Program menus in municipal schools \\ in Itapetinga - BA: food waste indicators
}

\section{Maria Celeste P. S. Nascimento리 Jussimara Barros de Oliveira², Gabrielle Cardoso Reis Fontan ${ }^{3}$ e Marcondes Viana da Silva ${ }^{4}$}

\begin{abstract}
${ }^{1}$ Mestrado em Ciências Ambientais, Universidade Estadual do Sudoeste da Bahia, Itapetinga, BA, Brasil
${ }^{2}$ Mestrado em Engenharia de Alimentos, Universidade Estadual do Sudoeste da Bahia, Itapetinga, BA, Brasil ${ }^{3}$ Doutorado em Ciência e Tecnologia de Alimentos, Universidade Estadual do Sudoeste da Bahia, Itapetinga, BA, Brasil ${ }^{4}$ Doutorado em Ciência e Tecnologia de Alimentos, Universidade Estadual do Sudoeste da Bahia, Itapetinga, BA, Brasil
\end{abstract}

\section{Resumo}

O desperdício de refeições escolares tem sido motivo de diversas investigações, considerando que este fato pode refletir no planejamento, processo produtivo, distribuição e adequação nutricional do cardápio oferecido às escolas. Objetivou-se neste estudo avaliar o desperdício alimentar através da aceitação e da adesão da alimentação escolar servida em três escolas públicas do Ensino Fundamental II da rede municipal de ensino, situadas no município de Itapetinga - BA. Foram utilizadas refeições servidas para 720 (setecentos e vinte) alunos de ambos os sexos, faixa etária de 10-17 anos, coletadas em dois períodos de distribuição da merenda escolar e aplicados questionários semiestruturados aos alunos. Verificou-se que a aceitabilidade da merenda escolar foi menor que $85 \%$, limite estabelecido pela legislação brasileira e que a merenda escolar não foi bem aceita pelos alunos, com base em suas preferências. A maioria dos alunos não tem o costume de repetir a refeição e avaliou como ideal os atributos sobre a aceitação das refeições. Das três escolas analisadas, duas apresentaram bons indices de adesão (superior a 80\%) e apenas uma delas verificou-se um baixo índice. Diante disso, sugere-se a realização de estudos explorando a correlação de fatores como a quantidade de alimentação produzida na escola, faixa etária e sexo.

Palavras-chave: alimentação escolar, desperdício, adesão, aceitabilidade.

\begin{abstract}
Studies on the waste of school meals has been reason for several investigations, considering that this might reflect in the planning, production process, distribution and nutritional adequacy of the menu offered to schools. Thus, the aim of the present study was to evaluate food waste through the acceptance and the school feeding membership served in three public schools of elementary school II of municipal school system, located in the city of Itapetinga - BA. In this study we used meals served to 720 (seven hundred and twenty) students of both sexes and aged 10 to 17 years old, collected in two periods of the school lunch distribution (morning and afternoon snacks). Were evaluated thirty (30) meals per shift (60 students daily), totaling 240 meals served per school. Semi-structured questionnaires were used for the students. It was found that the acceptability of school meals was less than $85 \%$ limit established by brazilian law and that the school meals was not well accepted by the students, based on their preferences. ost of the students even enjoying the food preparations served in schools, does not have the custom of repeating the meal and rated as ideal attributes on the acceptance of meals (seasoning, served temperature and quantity). The three analyzed schools, two indices showed good adhesion (exceeding 80\%) and only one was found to be low, adhesion index. Therefore, it is suggested to carry out studies exploring the correlation of factors such as the amount of power produced at school, age and sex.
\end{abstract}

Keywords: school feeding, waste, adherence, acceptability. 


\section{Introdução}

São crescentes os estudos relativos à quantificação de perdas e desperdícios de alimentos em todo o mundo. As perdas de alimentos se referem a um decréscimo da quantidade ou qualidade alimentar nas fases iniciais da cadeia alimentar, reduzindo assim, a quantidade de alimentos adequados para o consumo humano. O conceito perdas de alimentos, muitas vezes está relacionado com atividades póscolheita por deficiência no sistema produtivo ou capacidades de infraestrutura. Os resíduos alimentares, por outro lado, muitas vezes referem-se às fases da cadeia de abastecimento alimentar, tais como varejo e o consumo das famílias. Assim, as causas de desperdício de alimentos são frequentemente relacionadas com o comportamento humano (GUSTAVSSON, CEDERBERG e EMANUELSSON, 2013; LIPINSKI et al., 2013).

Estima-se que anualmente o desperdício global da produção agrícola, atinja 30\% para os cereais, 40-50\% para os tubérculos, frutas e legumes, $20 \%$ para as oleaginosas, carne e produtos lácteos e finalmente $35 \%$ para o pescado. É importante destacar que o Brasil é o quarto maior produtor de alimentos do planeta e, ao mesmo tempo, o sexto colocado no ranking mundial de desnutrição (CORRÊA et al., 2013; FAO, 2014).

Nesse contexto, a alimentação constitui uma relação direta com a saúde e qualidade de vida, sendo reconhecida como direito humano desde 1966, conforme estabelece o Pacto Internacional sobre Direitos Econômicos, Sociais e Culturais (BRASIL, 1996). Ademais, os alimentos constituem aporte nutricional para homeostase fisiológica através do fornecimento de energia, construção tecidual e regulação do metabolismo (CASEMIRO et al., 2014).

Movido por essa problemática, o Parlamento Europeu-PE destaca a tomada de medidas preventivas emergenciais quanto ao crescente desperdício alimentar, para evitar que o volume global do desperdício alimentar atinja um aumento de aproximadamente $40 \%$ na Europa, em 2020, o que representaria 126 milhões de toneladas de alimentos. "O desperdício de alimentos representa um problema ambiental e ético e tem custos econômicos e sociais, o que coloca desafios no contexto do mercado interno, tanto para as empresas como para os consumidores" (PE, 2012).

A alimentação e nutrição adequadas são condições básicas para o crescimento, desenvolvimento e saúde, sobretudo de crianças, considerando ainda que, uma alimentação adequada influencia determinantemente no rendimento escolar, uma vez que favorece a capacidade de concentração do aluno. Nessa perspectiva, em 31 de março de 1955, Juscelino Kubitschek de Oliveira assinou o Decreto n. 37.106, criando a Campanha da Merenda Escolar (CME). Posteriormente, em 1979, foi denominado Programa Nacional de Alimentação Escolar (PNAE), conhecido popularmente por "merenda escolar". Esse programa tem como objetivo atender às necessidades nutricionais dos estudantes, durante sua permanência em sala de aula, contribuindo para o seu crescimento, desenvolvimento, aprendizagem e rendimento escolar, bem como a formação de hábitos alimentares saudáveis.

Diversos estudos estão disponíveis na literatura explorando o desperdício alimentar nas escolas do ensino fundamental no Brasil (DIAS et al., 2013; LONGO-SILVA et al., 2013; ISSA et al., 2014). Entretanto, são limitados os estudos com essa temática no estado da Bahia, sendo esse pioneiro no município de Itapetinga.

Segundo Silvério e Oltramari (2014), a avaliação dos desperdícios alimentares pode contribuir como indicador da qualidade da refeição. Nesse contexto, os desperdícios podem refletir falhas no planejamento do número de refeições, na seleção de alimentos e sua preparação e ainda na definição das necessidades nutricionais da população alvo. Ademais, Moraes dos Santos e Pereira (2014) consideram também as questões financeiras, ambientais, éticas e sociais.

Pelo exposto, o interesse por essa problemática surgiu da necessidade de avaliar a aceitação e o desperdício alimentar em três escolas públicas do ensino fundamental no município de Itapetinga BA como uma contribuição para educação ambiental. Os dados coletados nesse estudo serão úteis 
para identificar as possíveis causas do desperdício além de servir como aporte para estimular futuros estudos relativo a essa temática.

\section{Material e métodos}

Este estudo foi conduzido no segundo semestre de 2014, em três escolas da rede municipal de ensino no município de Itapetinga - BA, nos turnos matutino e vespertino. Neste período, foram avaliadas 720 refeições servidas para os alunos do Ensino Fundamental II (6o ao 9o ano), de ambos os sexos, de idade entre 10 a 17 anos. Este estudo recebeu aprovação do Comitê de Ética em Pesquisa da Universidade Estadual do Sudoeste da Bahia sob o número 957.655.

As coletas de dados foram realizadas nos dois períodos de distribuição da merenda escolar, nos lanches da manhã (9h30 min) e da tarde (15h30min) durante 04 dias por escola. Em cada dia de aplicação dos questionários foram avaliados 30 (trinta) comensais por turno. Assim, foram investigados refeições de 60 alunos diariamente, totalizando 240 refeições servidas por escola. Durante a pesquisa foram realizadas aplicações de questionários semiestruturados aos alunos das escolas das unidades escolares.

Os cardápios escolares foram preparados por uma nutricionista do município e durante o período em que foi realizada a pesquisa foram oferecidas nas escolas municipais de Itapetinga-BA, quatro preparações distintas. Na Escola Sizaltina Silveira Souza Fernandes (SF) foi servido arroz doce, arroz tropeiro, mingau e cachorro-quente com suco e bolo, na Escola José Marcos Gusmão (JMG) o cardápio foi sopa, macarronada, pão com suco e pão com margarina e café com leite e o cardápio seguido na Escola Nair Jandiroba (NJ) foi pão com carne moída, arroz doce, sopa e suco com biscoitos.

\subsection{Instrumentos aplicados na pesquisa}

Para a condução da pesquisa foram utilizados instrumentos de coleta de dados para a obtenção das informações necessárias ao alcance dos objetivos propostos (questionários aplicados aos alunos).

Para avaliar o grau de aceitação das refeições servidas foram aplicados questionários para 720 (setecentos e vinte) alunos do Ensino Fundamental II. Utilizou-se a metodologia recomendada pela Resolução/CD/FNDE no 38/2009 (BRASIL, 2009). O questionário semiestruturado apresentava uma escala hedônica de cinco pontos, cujas opções de respostas variaram entre: desgostei muito, desgostei, não gostei e nem desgostei, gostei e gostei muito. Estes questionários consideraram os atributos tempero, temperatura e quantidade de alimentos servidos. Para obtenção do índice de aceitabilidade foi utilizado a seguinte equação:

Índice de aceitação (\%) = 100 - \% de rejeição

\section{Resultados e discussão}

Conhecer as preferências alimentares a partir da realização de diagnósticos torna-se importante na busca de maior aceitação e adesão dos alunos à alimentação oferecida no ambiente escolar (FNDE, 2010).

Estes diagnósticos de preferências alimentares contribuem para o processo de avaliação do desempenho do Programa Nacional de Alimentação Escolar (PNAE), através da análise de indicadores como a aceitabilidade e a adesão às refeições consumidas pelos alunos das unidades escolares (SILVA, 2001).

Dos 720 escolares do Ensino Fundamental II responderam ao questionário, 354 (49,17\%) eram do sexo masculino, com idades entre 10 e 17 anos e 366 (50,83\%) eram do sexo feminino, na faixa entre 10 e 16 anos. A média das idades dos escolares de ambos os sexos foi de 13 anos. 
3.1 Avaliação da aceitação da alimentação escolar nas escolas da rede municipal de ensino: Escola Sizaltina Silveira Souza Fernandes (SF), Escola José Marcos Gusmão (JMG) e Escola Nair D’ Esquivel Jandiroba (NJ)

Os resultados referentes à avaliação da aceitação da alimentação escolar nas escolas da rede municipal de ensino Escola SF, Escola JMG e Escola NJ encontram-se apresentados nas Figuras 1, 2 e 3

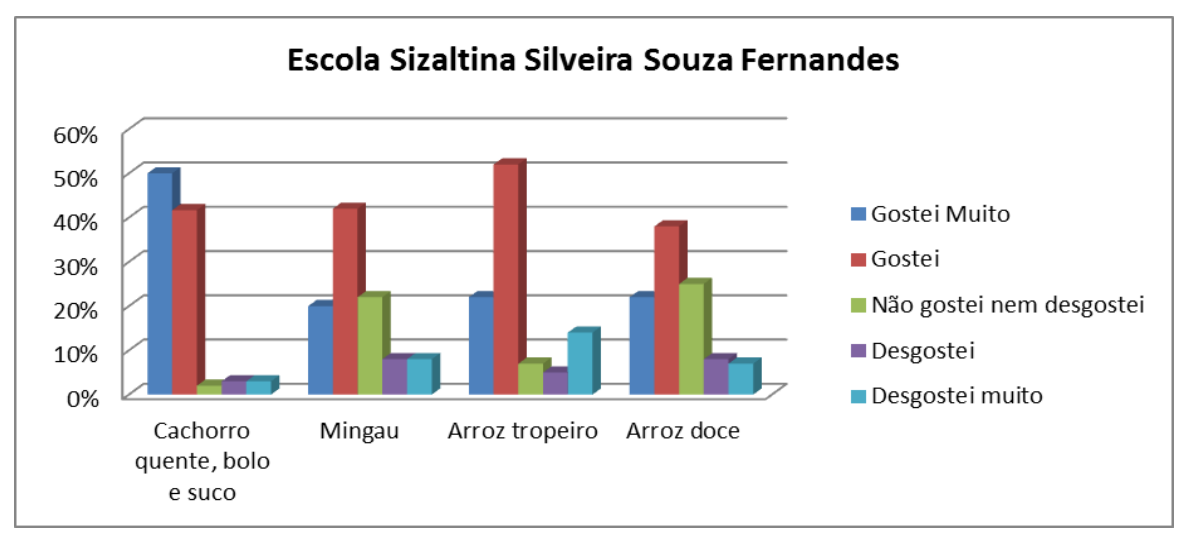

Figura 1. Avaliação da aceitação da merenda escolar na Escola SF

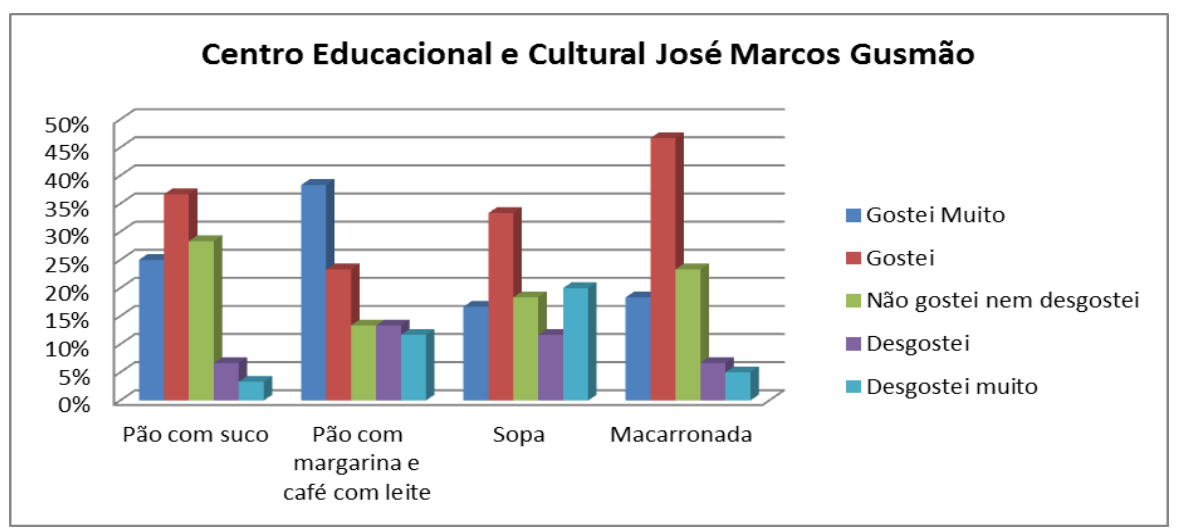

Figura 2. Avaliação da aceitação da merenda escolar da Escola JMG

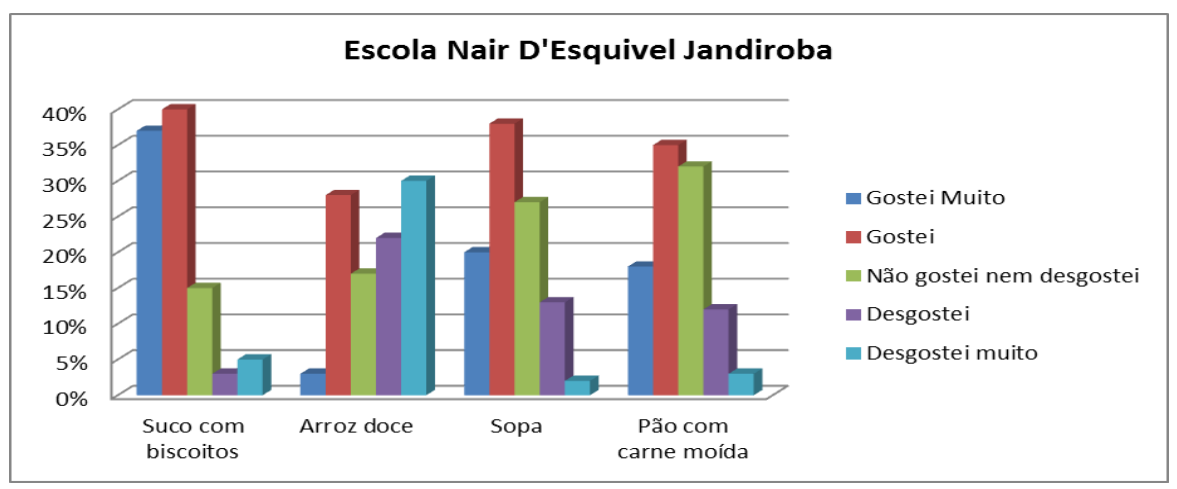

Figura 3. Avaliação da aceitação da merenda escolar da Escola NJ 
Os resultados apresentados na Figura 1 revelam que todos os itens do cardápio oferecidos na Escola SF foram bem aceitos pelos alunos, com destaque para a opção cachorro-quente, bolo e suco que apresentaram maiores índices de "gostei muito". Esse resultado pode ser justificado pela tendência dos alunos em associarem a alimentação escolar a um lanche e não a uma refeição. Vale ressaltar que, de um modo geral, os lanches rápidos são os que apresentam maiores preferências entre crianças e jovens, e que, a falta de adequação do cardápio escolar com suas preferências alimentares pode determinar sua baixa aceitação.

Essa associação entre lanche x refeição também foi observada nas escolas JMG (Fig. 2) e NJ (Fig. 3), onde as opções mais aceitas foram as que apresentavam características mais semelhantes com lanche, como é o caso do pão com margarina e café com leite (JMG) e suco com biscoitos (NJ).

Com base nos dados observados nas três escolas municipais percebe-se que o índice de aceitabilidade da merenda escolar foi menor que 85\%. Este índice não satisfaz a legislação brasileira, que, através de Resolução/FNDE/CD no 38, de 16 de julho de 2009, preconiza com base em parâmetros técnicos, sensoriais e científicos do PNA, que o índice de aceitabilidade não deve ser inferior a 85\% para ser considerado satisfatório (BRASIL, 2009).

Dias et al. (2013), analisando a qualidade, a aceitação e o resto ingestão da alimentação escolar oferecida em um Centro de Educação para jovens e adultos localizados na zona urbana de Cuiabá (MT) observaram índices de aceitabilidade superiores a $85 \%$ nos dois períodos analisados (matutino e vespertino), de um total de 280 alunos que realizaram as refeições.

A diferença de aceitação entre as preparações alimentares servidas aos alunos depende diretamente da preferência dos alunos e representa um condicionante do desperdício alimentar na merenda escolar.

Enquanto isso, a não aceitação da merenda escolar pode ser justificada pela falta de atratividade do cardápio, falta de preparações de suas preferências, inadequação da relação alimento x faixa etária, aceitação esporádica da refeição, falta de apetite, dentre outros fatores. Algumas frases descritas a seguir reforçam essa ideia: "porque não gosto", "porque às vezes eu não gosto do tipo da merenda", "porque meus pais me dão dinheiro pra comprar na cantina" e "porque não tenho fome pela manhã".

\subsection{Avaliação dos atributos (tempero, temperatura e quantidade servida) sobre a aceitação das refeições oferecidas nas escolas}

Os resultados da avaliação dos atributos (tempero, temperatura e quantidade servida) sobre a aceitação das refeições oferecidas nas escolas encontram-se apresentados nas Figuras 4, 5 e 6.

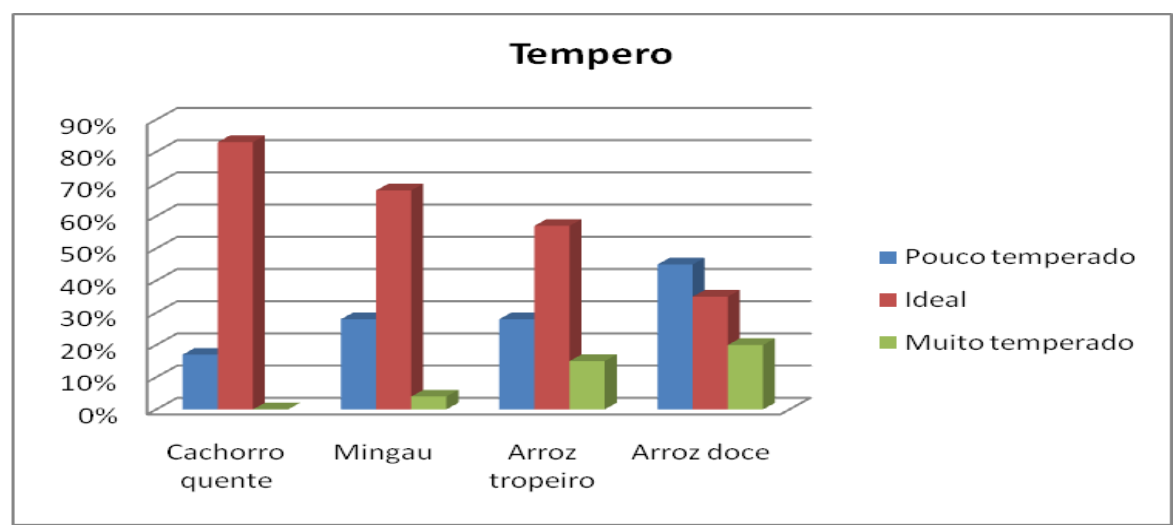

Figura 4(a). Avaliação do atributo tempero sobre a aceitação das refeições oferecidas na Escola SF 


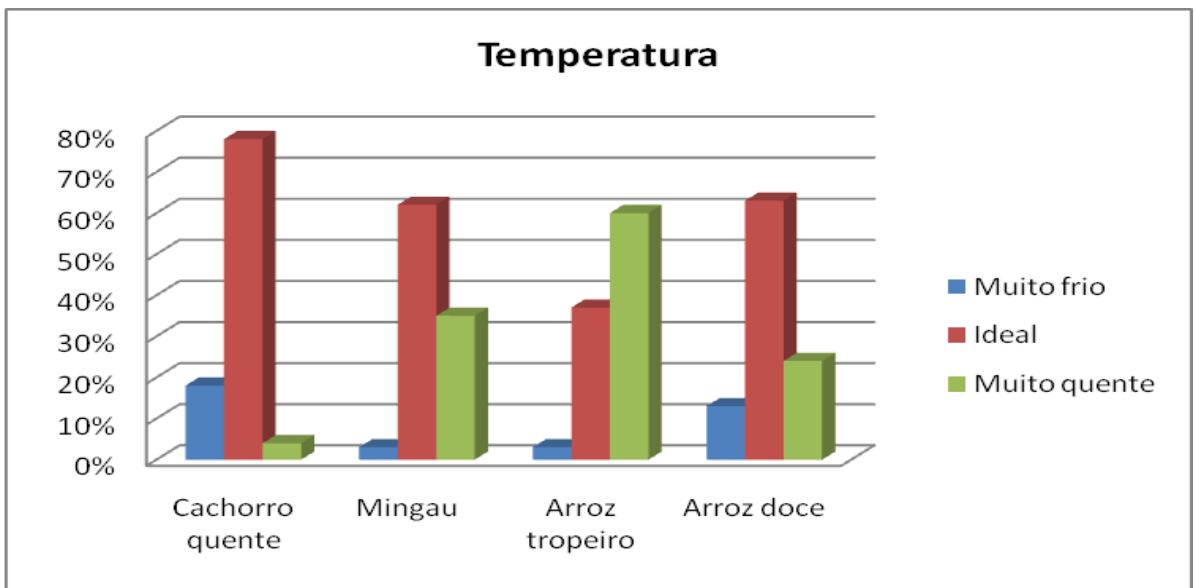

Figura 4 (b). Avaliação do atributo temperatura sobre a aceitação das refeições oferecidas na Escola SF

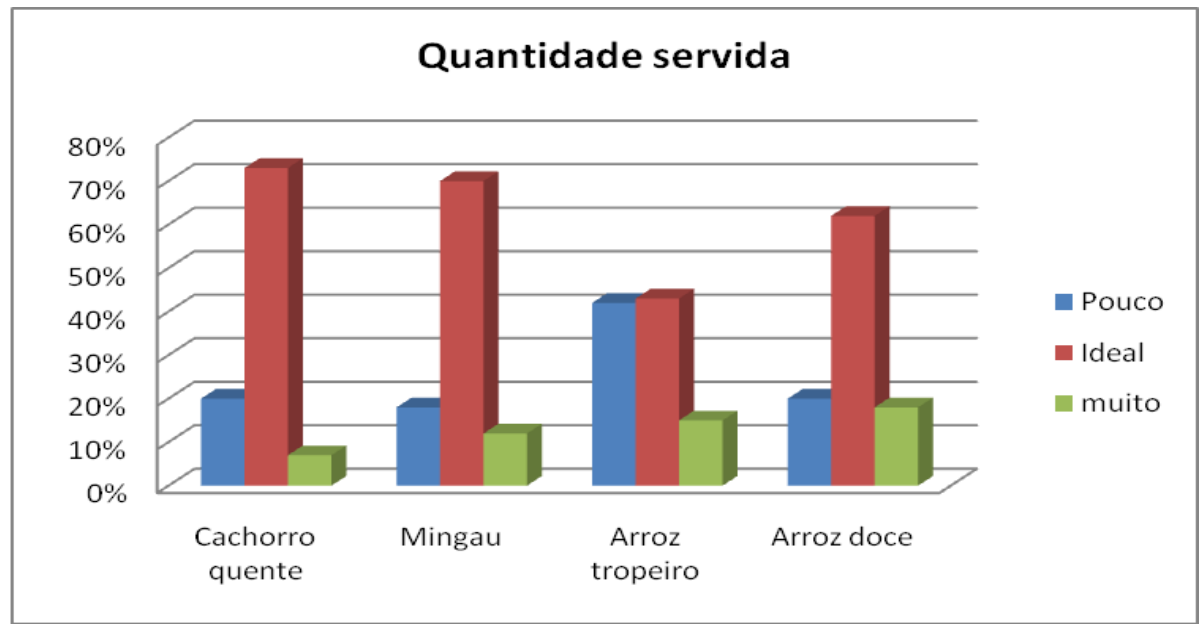

Figura 4 (c). Avaliação do atributo quantidade servida sobre a aceitação das refeições oferecidas na Escola SF

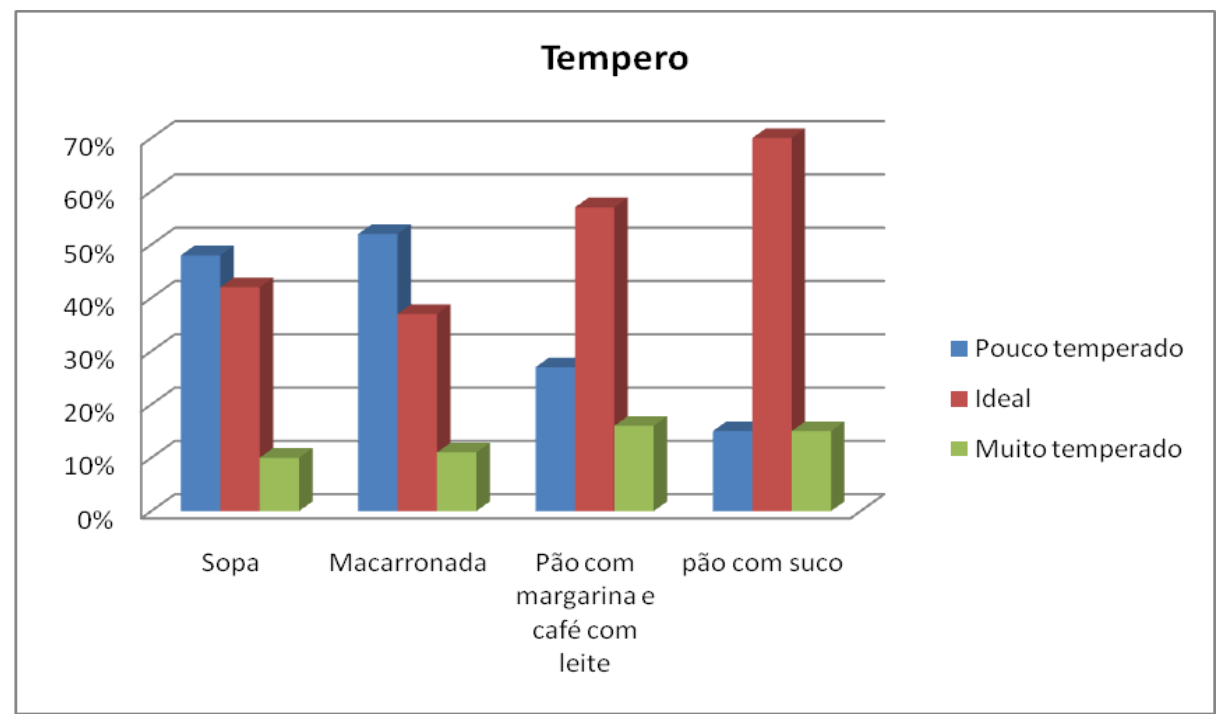

Figura 5 (a). Avaliação do atributo tempero sobre a aceitação das refeições oferecidas na Escola JMG 


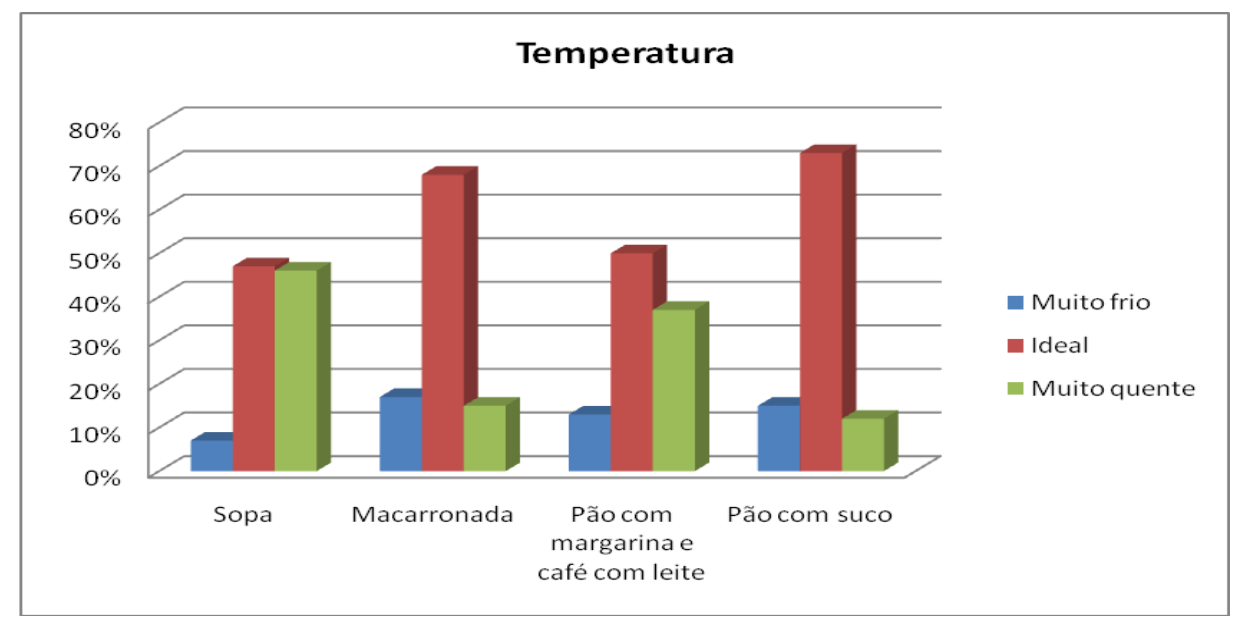

Figura 5 (b). Avaliação do atributo temperatura sobre a aceitação das refeições oferecidas na Escola JMG

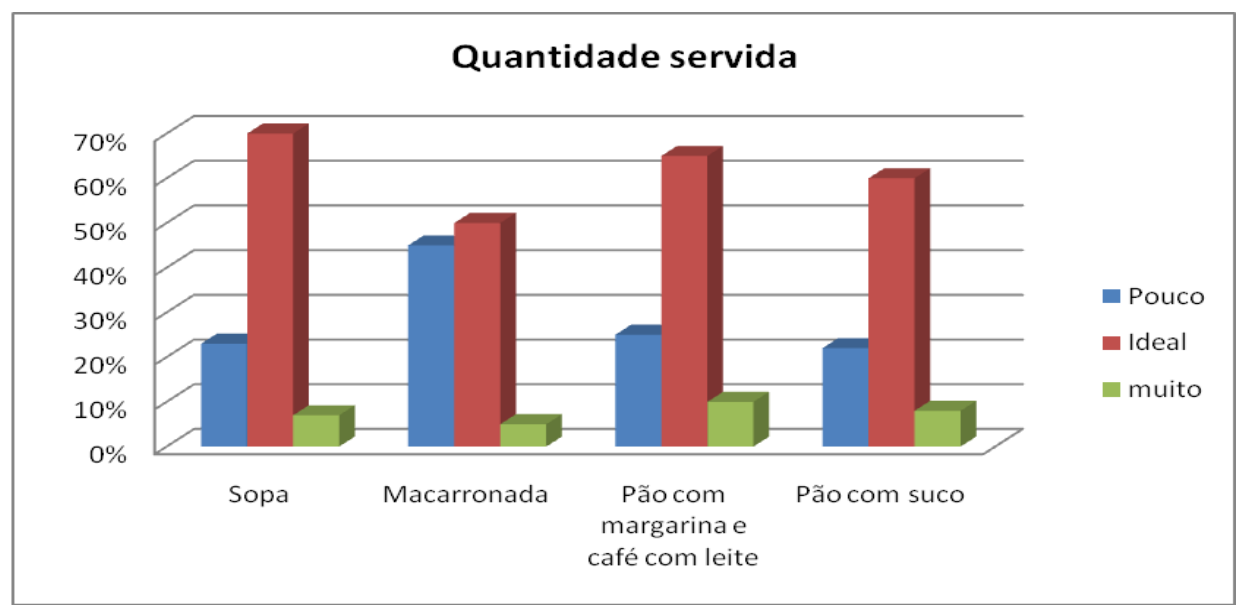

Figura 5 (c). Avaliação do atributo quantidade servida sobre a aceitação das refeições oferecidas na Escola JM

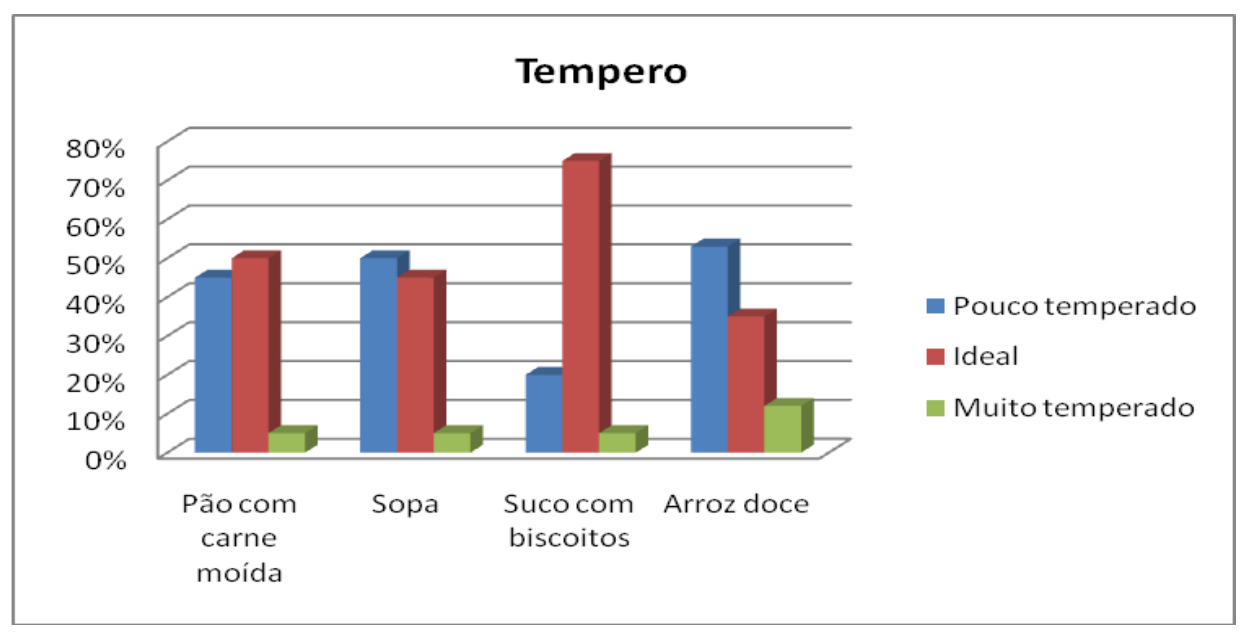

Figura 6 (a). Avaliação do atributo tempero sobre a aceitação das refeições oferecidas na Escola 


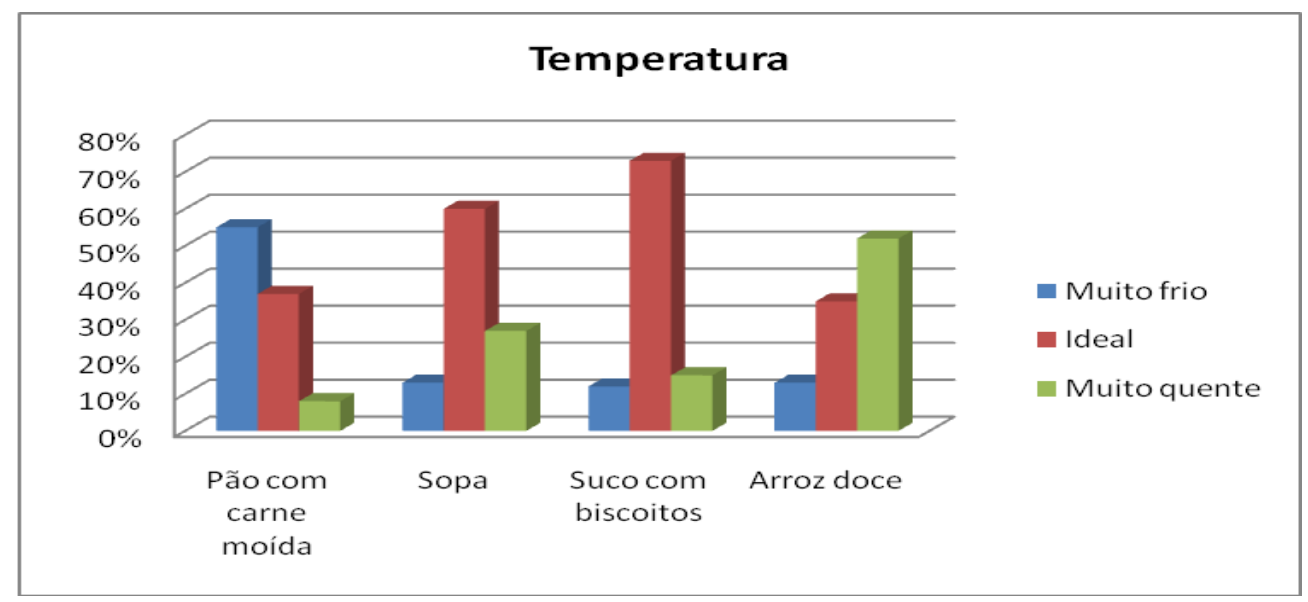

Figura 6 (b). Avaliação do atributo temperatura sobre a aceitação das refeições oferecidas na Escola NJ

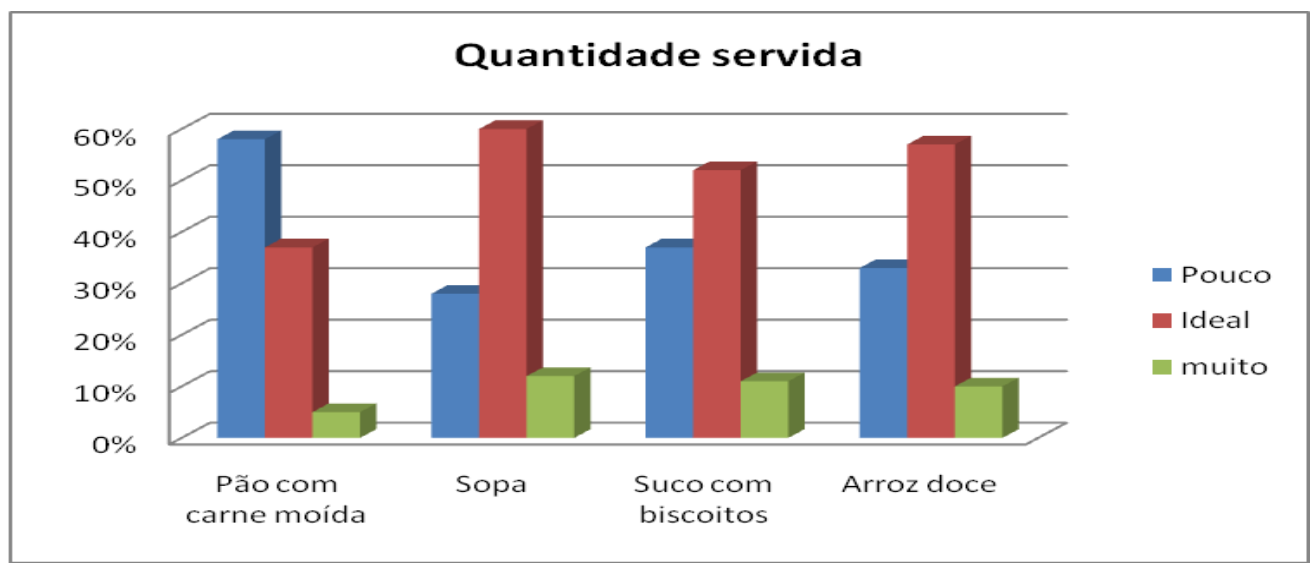

Figura 6 (c). Avaliação do atributo quantidade servida sobre a aceitação das refeições oferecidas na Escola NJ

A temperatura é um atributo importante que interfere na aceitação das refeições consumidas, tendo em vista que cada refeição apresenta características particulares quanto à ingestão. A sopa, por exemplo, no geral, é uma preparação alimentar que, pela sua natureza, costuma ser servido numa temperatura mais elevada, o que parece ter uma maior aceitação.

No que se refere aos resultados encontrados nas três escolas municipais do Ensino Fundamental II do município de Itapetinga analisadas, a maioria dos alunos $(56,91 \%)$ responderam que a temperatura das refeições servidas nos dias pesquisados é ideal.

O tempero é também um atributo importante que pode influenciar no consumo de alimentos, além de que seu excesso pode estar associado a problemas à saúde. Como exemplo disso, podemos citar o cloreto de sódio (sal), um estimulador do apetite e modulador do sabor (LESHEM, 2009). A sua presença em excesso na preparação alimentar tende não apenas a limitar o consumo da alimentação servida, como também contribui para o surgimento de doenças como a hipertensão arterial.

Bouhlal et al. (2011), avaliando a aceitação de diferentes preparações com teores distintos de sal e gordura, consideraram níveis baixos a altos de cloreto de sódio e manteiga adicionados em feijão e macarrão (0, 0,6 e 1,2\% para o sal e $0,25,2,5$ e 5\% para a gordura). No que se refere à adição de sal, 
estes autores identificaram que o nível de sal adicionado teve impacto na aceitação, sendo que quanto maior adição, melhor aceitação.

Ainda com relação às justificativas dos comensais, a maioria dos alunos (54,5\%) também considerou que o tempero das refeições servidas é ideal e 58,25\% responderam que a quantidade servida também é ideal, resultado que pode ser considerado positivo.

A refeição menos aceita (arroz doce) na Escola SF foi considerada pelos alunos como deficiente em termos de sabor, onde estes alegaram pouco tempero, comprometendo assim, a aceitabilidade da opção do cardápio da alimentação escolar.

Já na Escola JMG os alunos alegaram que a sopa estava pouco temperada e muito quente, embora a quantidade servida estivesse em condições ideais, o que justifica ser a refeição com menor índice de aceitação. Na Escola NJ esse fenômeno se repete, onde os alunos alegaram, como justificativa da menor aceitação do arroz doce, a insuficiência de tempero e alta temperatura. Isto indica que as características sensoriais dos alimentos servidos, como temperatura e sabor, determinam a aceitação da refeição, além de contribuir para o desperdício de alimentos.

\subsection{Avaliação da adesão e grau de satisfação dos alunos quanto à merenda escolar}

Os resultados obtidos para a adesão à alimentação oferecida nas três escolas municipais do Ensino Fundamental II do município de Itapetinga e para o grau de satisfação dos alunos quanto à merenda escolar estão apresentadas nas Figuras 7, 8 e 9.

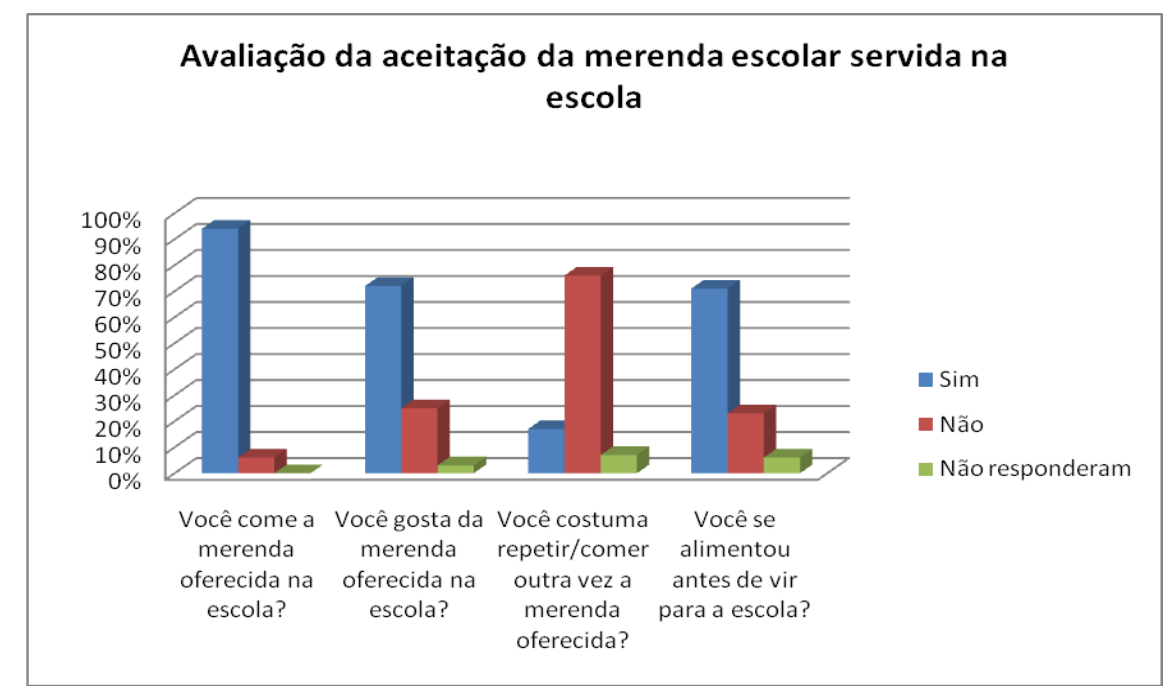

Figura 7. Avaliação da adesão e grau de satisfação dos alunos da Escola SF quanto à merenda escolar 


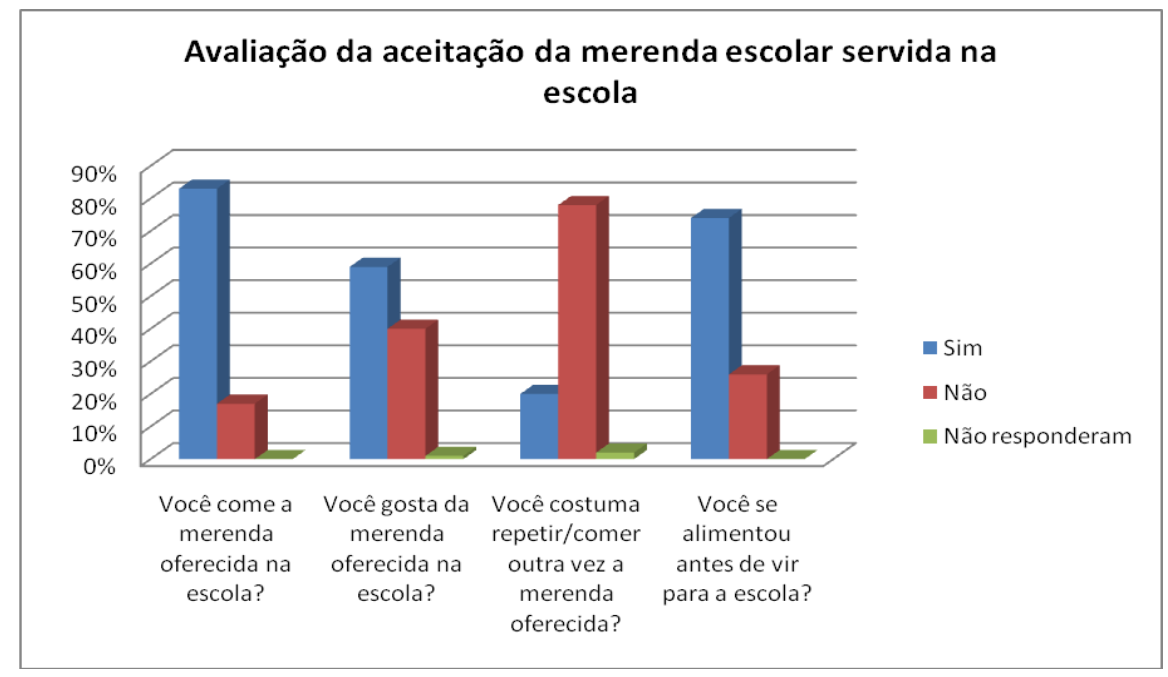

Figura 8. Avaliação da adesão e grau de satisfação dos alunos da Escola JMG quanto à merenda escola

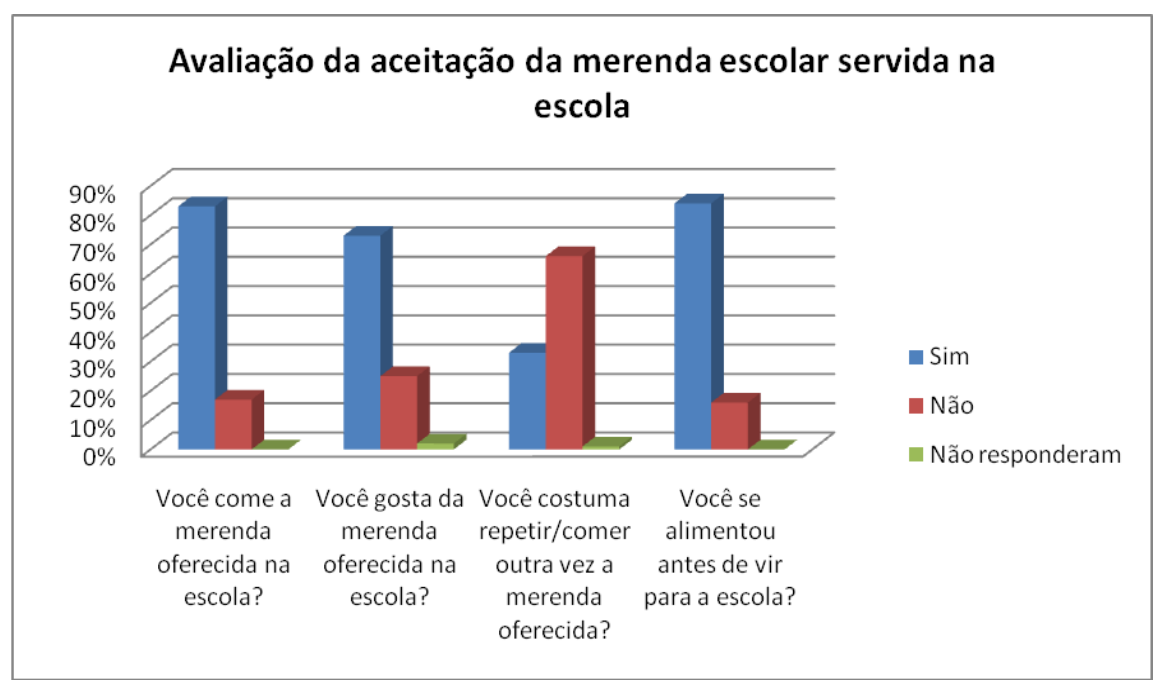

Figura 9. Avaliação da adesão e grau de satisfação dos alunos da Escola NJ quanto à merenda escolar

Com base nos dados analisados, observou-se um baixo índice de adesão à merenda na Escola JMG (57\%). Nesta Escola a faixa etária dos alunos era maior, variando entre 14 e 17 anos, fato que pode justificar a baixa adesão, tendo em vista que estes alunos não gostam de submeter à fila de distribuição de merenda, preferindo utilizar o tempo livre para socializar entre os colegas.

Enquanto isso, as Escolas SF e NJ apresentaram bons índices de adesão, 83\% e 94\%, respectivamente. Alguns estudos têm apontado que as refeições oferecidas nas escolas tornam-se importantes, dentre outros fatores, devido à dificuldade financeira de muitas famílias, que por sua vez, contam com essa possibilidade oferecida pela escola como forma de garantir alimentação adequada aos filhos (MUNIZ e CARVALHO, 2007).

Resultado semelhante ao encontrado no presente estudo foi observado por Danelon (2007), cujo percentual de adesão ao programa de alimentação escolar foi de $75,3 \%$ dos escolares de Campinas-SP. Enquanto isso, Muniz e Carvalho (2007), analisando a adesão e a aceitação da alimentação escolar em 
240 escolares de escolas da rede pública municipal do ensino fundamental observaram que o índice de adesão foi superior a $90 \%$.

A adesão ao programa de alimentação escolar é influenciada por diversos fatores que vão desde problemas de temperatura, oferecimento de preparações inadequadas aos horários de distribuição, tipo de refeição servida que não atende a preferência dos escolares, qualidade higiênico-sanitária das refeições distribuídas, pouco tempo para consumo da alimentação, local inadequado e desorganização na distribuição das refeições (STURION, 2002).

A maioria dos alunos (68\%) analisados no presente estudo respondeu que gostam das preparações alimentares servidas no ambiente escolar. Aqueles que responderam não consumir a merenda oferecida na escola apresentaram justificativas distintas. Dentre elas, alegaram que preferem comprar alimentos na cantina; não gostam da merenda servida; a refeição tem pouco tempero e que não tem fome pela manhã.

Vale ressaltar que, durante a aplicação dos questionários aos alunos nas escolas, observou-se no momento da distribuição da merenda escolar a formação de filas extensas, e ainda, que muitos alunos deixavam de merendar para não ter que enfrentar a fila formada, pois preferiam aproveitar o intervalo reservado para o lanche para socialização.

No que refere ao grau de satisfação, apenas $23,3 \%$ dos alunos alegaram ter o costume de repetir a merenda oferecida, enquanto que a maioria $(76,7 \%)$ não repete a refeição. E, quando questionados se os alunos se alimentaram antes de se deslocar para a escola, a maior parte $(76,3 \%)$ dos entrevistados afirmou que sim. Dessa forma, pode-se inferir que a alimentação realizada pelos alunos em seus domicílios, antes de se descolarem às escolas, influencia na necessidade que os comensais apresentam em repetir ou não a porção oferecida da merenda escolar.

Constatou-se nesse estudo que embora tendo disponibilidade de merenda na escola, os alunos preferem obter a primeira refeição do dia em suas casas. Esse hábito constitui um fator positivo, uma vez que no Brasil a distribuição da merenda nas escolas geralmente é oferecida às 10 horas. Espaço de tempo considerado muito longo para que os alunos fiquem sem se alimentar, considerando a ultima refeição do dia anterior, isso pode comprometer desempenho no aprendizado escolar. Esta verificação também foi observada por Mota et al. (2013) quando avaliaram o consumo da refeição escolar na rede pública municipal de ensino.

\section{Conclusões}

Para além de uma simples refeição, a alimentação escolar apresenta, no contexto educacional, uma relação direta com a qualidade de vida do aluno e influencia de forma determinante no seu rendimento escolar, por propiciar condições que favorecem a capacidade de concentração, e consequentemente, a aprendizagem.

Ainda que este estudo tenha tido algumas limitações como as faixas etárias que não foram analisadas separadamente, fato que pode super ou subestimar os resultados, e, a alteração dos cardápios propostos pela nutricionista, os dados encontrados neste estudo constituem fonte importante sobre o Programa de Alimentação Escolar em escolas públicas do Ensino Fundamental II da rede municipal de ensino do município de Itapetinga-BA.

Os resultados indicam que a aceitabilidade da alimentação escolar nas unidades escolares avaliadas foi baixa, comprometendo assim a eficácia do Programa de Alimentação Escolar. Das três escolas analisadas, duas apresentaram bons índices de adesão (superior a $80 \%$ ) e apenas uma delas verificou-se um baixo índice. Constatou-se que a merenda escolar não foi bem aceita pelos alunos, pois conflitam com suas preferências. A maioria dos alunos, mesmo gostando das preparações alimentares servidas nas escolas, não tem o costume de repetir a refeição porque não gostam das opções do cardápio, por não desejar perder tempo na fila ou por não estar com fome o bastante para isso. 
Diante desses aspectos sinalizados, sugere-se o planejamento de ações educativas relacionadas à nutrição e saúde que possibilitem aos estudantes a mudança de hábitos alimentares e ainda, a participação na produção de itens que comporão os cardápios da alimentação escolar. Destacam-se ainda a necessidade de adoção de outras medidas para o enfrentamento do cenário observado, como horário diferenciado para a alimentação de algumas turmas, adequação dos refeitórios permitindo que os alunos disponham de espaço satisfatório para se alimentarem e sistematização da distribuição da alimentação com investimento em recursos humanos.

Essas ações podem contribuir de forma significativa para a redução das extensas filas formadas, o aumento da adesão e aceitabilidade da alimentação escolar oferecida nas escolas e o fornecimento de uma alimentação adequada nutricionalmente, melhorando assim, os índices do Programa de Alimentação Escolar e principalmente, a qualidade de vida dos alunos, que refletirá diretamente no processo de aprendizagem. Dada a complexidade do assunto em estudo, vale ressaltar ainda, a importância da realização de estudos explorando a correlação de fatores como a quantidade de alimentação produzida na escola, faixa etária e sexo.

\section{Agradecimentos}

À Secretaria de Educação Municipal de Itapetinga, especialmente a direção das escolas nas quais a pesquisa foi realizada.

\section{Referências}

BOUHLAL, S., ISSANCHOU, S., NICKLAUS, D. The impact of salt, fat and sugar levels on toddler food intake. British Journal of Nutrition, v.105, p. 645-653, 2011.

BRASIL, Ministério da Educação. Fundo Nacional de Desenvolvimento da Educação. Resolução/CD/FNDE n. 38/2009. Dispõe sobre o atendimento da alimentação básica no Programa Nacional de alimentação Escolar. 2009. Disponível em: http://www.fnde.gov.br.Acesso em: 17 de out. 2014.

BRASIL. Lei no 9.394, de 20 de dezembro de 1996. Lei de Diretrizes e Bases da Educação Nacional. Diário Oficial da União, Brasília, DF, 24 dez. 1996. Disponível em http://portal.mec.gov.br/seed/arquivos/pdf/tvescola/leis/lein9394.pdf. Acesso em 10 de mar. 2015.

CASEMIRO, J. P.; FONSECA, A. B. C.; SECCO, F.V.M. Promover saúde na escola: reflexões a partir de uma revisão sobre saúde escolar na América Latina. Ciência \& Saúde Coletiva, v.19, p. 829-840, 2014.

CORRÊA, C.; GITEL, M.; SANDES, J.; TOURINHO, L.L.R.; COSTA, K. Do campo à cidade: soluções para o desperdício de alimentos. 2013. Disponível em: <www.ecod.org.br>. Acesso em: 19 mar. 2015.

DIAS, P.H. A.; KINASZ, T. R.; CAMPOS, M. P. F. F. Alimentação escolar para jovens e adultos no munícipio de Cuiabá-MT: um estudo sobre a qualidade, aceitação e resto ingestão. Alimentos e Nutrição, v. 24, p. 79-85, 2013.

FUNDO NACIONAL DE DESENVOLVIMENTO DA EDUCAÇÃO (FNDE). 2010.

GUSTAVSSON, J.; CEDERBERG, C.; EMANUELSSON, U.S.A. The Swedish Institute for Food and Biotechnology - SIK. The methodology of the FAO study: "Global Food Losses and Food Waste extent, causes and prevention"- FAO, 2013. SIK report No. 857. 2013. 
ISSA; R.C.; MORAES; L.F.; FRANCISCO, R.J.; SANTOS; L.C.; ANJOS DOS; A.F.V. PEREIRA, S.C.L. Alimentação escolar: Planejamento, produção, distribuição e adequação. Revista Panamericana de Salude Pública, v. 35, p. 93-103, 2014.

LESHEM, M. Biobehavior of the human love of salt. Neuroscience Biobehavioral Reviews, v. 33, n.1, p.1-17, 2009.

LONGO-SILVA; G.; TOLONI; M.; RODRIGUES, S.; ROCHA, A.; TADDE, J.A.A.C. Qualitative evaluation of the menu and plate waste in public day care centers in São Paulo city, Brazil. Revista de Nutrição, v. 26, p. 135-144, 2013.

MOTA, C. H.; MASTROENI, S. S. B. S.; MASTROENI, M. F. Consumo da refeição escolar na rede pública municipal de ensino. Revista Brasileira de Estudos Pedagógicos, v. 94, n.236, p. 168-184, 2013.

MUNIZ, V. M.; CARVALHO, A, T. O. Programa Nacional de Alimentação Escolar em município do estado da Paraíba: um estudo sob o olhar dos beneficiários do Programa. Revista de Nutrição, v. 20, n. 3, p. 1-19, mai.jun., 2007.

PARLAMENTO EUROPEU-PE. Proposta de Resolução do Parlamento Europeu - Como evitar o desperdício de alimentos: estratégias para melhorar a eficiência da cadeia alimentar na UE. Comissão da Agricultura e do Desenvolvimento Rural; 2012.

SILVÉRIO, G. A.; OLTRAMARI, K. Desperdício de alimentos em Unidades de Alimentação e Nutrição brasileiras. Revista do Setor de Ciências Agrárias e Ambientais, v. 10, p. 125-133, 2014.

STURION, G. L. Programa de alimentação escolar: avaliação do desempenho em dez municípios brasileiros. [tese]. Campinas: Universidade Estadual de Campinas. 2002. 269p. 